\title{
Using problem-based learning in public health service based training
}

\author{
Gaynor S. Heading ${ }^{\mathrm{A}}$, Jeffrey D. Fuller ${ }^{\mathrm{B}, \mathrm{D}}$, \\ David M. Lyle ${ }^{\mathrm{A}}$ and D. Lynne Madden ${ }^{\mathrm{C}}$ \\ ${ }^{\mathrm{A} B r o k e n ~ H i l l ~ C e n t r e ~ f o r ~ R e m o t e ~ H e a l t h ~ R e s e a r c h, ~ B r o k e n ~ H i l l ~}$ \\ University Department of Rural Health, University of Sydney \\ ${ }^{\mathrm{B} N o r t h e r n ~ R i v e r s ~ U n i v e r s i t y ~ D e p a r t m e n t ~ o f ~ R u r a l ~ H e a l t h, ~}$ \\ University of Sydney and Southern Cross University \\ ${ }^{\mathrm{C}}$ Public Health Training and Development Branch, NSW \\ Department of Health \\ DCorresponding author.Email: jeffreyfuller@nrahs.nsw.gov.au
}

\begin{abstract}
Objectives: This study explored the suitability and benefits of problem-based learning (PBL) in competency-based postgraduate public health training. The PBL was delivered within a rural retreat and included site visits. Methods: Qualitative semistructured interviews with trainee public health officers and key informants. Results: The learning approach (retreat-PBL combination with site visits) was valuable and relevant. Trainees reported a high learning impact with increased knowledge about the problems examined and rural public health practice. They also expressed an openness to work rurally. Conclusion: Collaboratively developed and delivered, experiential rural public health PBL provides a positive learning experience for trainees undertaking competency-based training in public health and could play an important workforce role. PBL appears to be suitable in rural and non-rural public health training settings.
\end{abstract}

Problem-based learning (PBL) is valued in undergraduate health science curricula as a means of developing critical thinking, problem-solving skills, teamwork skills and the ability to deal with complexity ${ }^{1}$ - all attributes considered important for public health practice. The distinguishing features of PBL include active self-directed learning where small tutor-facilitated groups encounter a problem and then seek solutions, with no advanced readings or lectures. ${ }^{2}$ The method involves learners exploring their preexisting knowledge and seeking additional information to advance their understanding. ${ }^{2}$ Active participation leads to more satisfying learning ${ }^{3}$ and greater knowledge and clinical reasoning skills. ${ }^{4}$ PBL has focused mainly on clinical situations; however, population problems can effectively be used when they use 'progressive disclosure', reflect 'real-life situations', and have a broad title that directs thinking to population issues. ${ }^{5}$ While the inclusion of PBL in undergraduate public health education appears sound, ${ }^{6}$ its suitability has largely been ignored in professional training. ${ }^{7}$

During November 2005, nine trainees, seven in their final year of the NSW Public Health Officer Training Program (the Program), who had completed a 6-month rural rotation, and two from linked programs, participated in a week-long rural training retreat that incorporated PBL. The retreat was held in Broken Hill, a small city in arid Australia located $1200 \mathrm{~km}$ west of Sydney (where the Program is based). The retreat included active learning about the communities located along the rail corridor that trainees travelled through during a 12-hour train trip from Sydney to Broken Hill; a 4-day PBL on water quality (a major public health issue in Broken Hill); site visits; and meetings with public health professionals. The PBL involved three facilitated sessions over 4 days. The first session focused on the scenario, problem identification, information gathering and problem reformulation; the second session considered options for solving the problem; and the third session addressed emerging issues and discussion points.

The development of a public health PBL scenario for the Program was the initiative of the NSW Department of Health and arose from an interest in exploring new ways in which to deliver service-based training. The Broken Hill University Department of Rural Health was contracted to develop the PBL scenario, and this was accomplished in consultation with key stakeholders, including staff from the Program.

The study explored the benefits that exist for trainee public health officers who undertake rural training within a retreat that incorporates a public health PBL exercise and how well this fits with the delivery of a competency-based postgraduate training program. The impact and desirability of new ways of delivering public health training through active on-site learning about rural public health issues and communities involving PBL and site visits (including the train journey) were examined. 


\section{Methods}

Data collection for the evaluation of the training package was by qualitative means. Semistructured in-depth interviews averaging 30 minutes in duration were undertaken with 19 respondents (all nine trainees and 10 key informants). Key informants were staff involved in the retreat planning or PBL delivery from the Program, Greater Western Area Health Service Population Health Unit and two university departments of rural health. They were invited to participate in the evaluation by two of the authors (GH or JF). Two potential key informants were not available at the time of interview. Interviewing commenced the week after the training finished and took about 3 weeks. All respondents gave informed consent. Interviews were taperecorded, with notes typed into a word-processor file. Data were separately coded (by GH and JF) with cross-coder verification. There was high agreement between coders. A few minor differences in interpretation were discussed and agreement was reached about a thematic framework. The evaluation explored the: (a) value of a PBL approach within a training retreat; (b) learning impact; and (c) factors to explain the effectiveness of this means of delivery. The results section presents the findings for the first two points while the value of retreat-style training that incorporates $\mathrm{PBL}$ is explored in the discussion section.

\section{Results}

Trainees (three male and six female) liked the practical focus of the retreat and the PBL, and also the hospitality they received in Broken Hill. The key informants involved in the development of the PBL and its delivery wanted to know if it would work, and were pleased with the trainees' engagement with the exercise. The local public health unit staff were satisfied with their involvement, as the exercise allowed them to reflect on their work and to see the problem examined in a broader context (Box 1, quotes $1-2)$.

\section{The learning approach}

While experiential learning was the most valuable aspect of the retreat, there were a few minor problems such as the 3-hour delay in the departure of the train from Sydney. While the delay added frustration to a long trip, the journey was designed as a learning opportunity, introduc-

\section{Box 1. Satisfaction (quotes 1-2)}

1. In hindsight it feels that it worked better than a lot of other training that is theoretical and removed from the real world. There should be more of it. (Trainee 6)

2. I think it is a good opportunity for people to sit back and look at what they do ... and take some method to pull it all together ... There is a tendency to be a bit on our own out here and so it is good to bring them [public health unit staff] into a bigger network and have them exposed to a group of [public health officer trainees] and to think about different ways to approach problems. (Key Informant 3) ing trainees to rural issues including the realities of travelling to remote locations (Box 2, quote 3).

There was unanimous support for the use of a PBL exercise and learning in situ. The benefit of studying remote public health issues through a PBL exercise in a rural location was recognised as having an impact bigger than being in [the city]'. Trainees were happy with the pace of learning and length of the training and valued having access to experts, local professionals, site visits and written resources. More than half of the trainees commented on the resources and how the PBL was supported by 'easy access to information' and 'experts', which allowed 'clarity and guidance'. A few thought that it would have been better if they had to undertake more of a 'mental hunt down' for appropriate resources; however, others noted that easy access to resources was beneficial given that only 4 days were available for the PBL.

Trainees enjoyed the engaging nature of the PBL. The retreat-PBL combination created a 'variety of learning experiences' and trainees appreciated how the PBL topic had 'complexity that unfolded gradually'. According to the trainees, this made the training realistic, relevant, practical and 'learner centred' (Table 2, quotes 4-6). There was some criticism, however, when a site visit was not linked well to the PBL and did not capitalise on an expected learning opportunity. This experience illustrated the effort required to maximise the learning potential from site visits.

The focus on one public health issue in one location did limit trainees' exposure to a broad range of rural and remote public health issues and about half of the trainees expressed the desire to have explored additional environ-

\section{Box 2. Experiential learning (quotes 3-6)}

3. [It was] important that at least one trip was made by train to impart ... the concept of distance ... and what isolation might mean. [The three hour] train malfunction may have been negative for a few Trainees, but this was very realistic, as people travelling to remote locations do not have many travel choices and if the train is late and there is no plane to quickly jump on ... you have no choice under such circumstances. (Key Informant 18)

4. It would be hard to imagine what a town would be like. (Trainee 1)

5. Site visits helped to increase understanding because I could see things, which helps to put these things into a practice context. It was good to see ... the lake system and what we are talking about to put that back into our discussion in our small groups. This was about a public health problem. It was and kept unfolding and changing and continued to evolve as we got into it. (Trainee 2)

6. The training was not too pressured so you could immerse yourself in the environment and absorb things rather than just the textbook experiences. (Trainee 4) 
mental health and Aboriginal health issues. Other trainees, however, reported that dealing with one problem enabled them to gain a deeper understanding of the principles of public health practice. Moreover, additional content would have limited their immersion in the historical, cultural and social context in which the problem arose. As public health strategies are implemented within and influenced by local context, experiencing this is a relevant and important aspect of learning.

\section{Learning impact}

The perceived relevance of PBL to public health training was in the development of problem solving and teamwork competencies in a simulated real world context (Box 3, quotes 7-9). While trainees reported increased knowledge about water quality, the more profound and surprising impact for them was to see the mutually supportive form of public health practice that has developed in Broken Hill.

\section{Box 3. Learning impact (quotes 7-14)}

7. The PBL approach is as close to real as you can get. The students had to work as a team and get resources and to then think about the consequences of their decisions. (Key Informant 6)

8. [In] most of the training ... we bring in experts ... around single competency areas. That doesn't really reflect what these guys do on the job, most of the time they are usually working around several competency areas at any one time. (Key Informant 12)

9. You have to go through the analytic process that would be encountered in real practice. (Trainee 4)

10. The unique aspect was the extent to which those in the local community support each other. I expected that I would find people working in stand-alone situations and relying on accessing public health specialist expertise in Sydney. I expected I would find more of them working in professional isolation. (Trainee 2)

11. I have an increased understanding of the nuances, that is, that the negative aspects, such as isolation, also have positive aspects, such as leading to closer working relationships. (Trainee 4)

12. I'm open to Broken Hill but can't generalise. It doesn't mean I'm open to all rural. A rotating position (secondment) as part of a program would be good ... The type of work will influence. A six to twelve-month's secondment would be good. (Trainee 1)

13. While my views have not changed regarding the issues of distance and isolation, I did see the support structures that are available in Broken Hill, particularly how there are close partnerships between professionals that collectively increase their resources ... [and] technology such as videoconference that reduces isolation. (Trainee 2)

14. When in a new environment [I] will get out and drive around and take photos, not just sit and look at the map. Get out and see for myself. It has always worried me how [some practitioners] never visit to see how things work. The PBL reinforced that we can all be a bit lazy. Actually meeting people really reinforced that need. (Trainee 5)
While this has been born of necessity due to distance from other public health specialists, it has been actively cultivated by local practitioners (Box 3, Quotes 10-11). The awareness that distance did not mean absolute professional isolation appeared to open a few trainees to the possibility of future remote public health work (Box 3, quotes 12-13).

While the impact of PBL in a 1-week retreat may be limited, one trainee made the point that the impact was amplified by the magnitude of the difference between urban Sydney and Broken Hill. The impact of training held in less-isolated rural settings is worth exploring. Another trainee noted the importance of undertaking site visits to develop a sound understanding of a location and the related issues. They reported how the retreat-PBL had confirmed for them the value of undertaking site visits and how they would build these into future work practice (Box 3, quote 14).

\section{Discussion}

The retreat-PBL approach appears to be constructive and is aligned with the aims of the Program, which is to produce graduates who are competent to work strategically with other public health practitioners to resolve public health issues in NSW. This learning approach also requires the simultaneous application of many of the competency areas from the competency framework on which the Program is based. ${ }^{8}$ Further, it augments the learning that trainees gain during the 6-month rural work experience that they are required to undertake.

The learning principles underpinning the PBL are aligned with contemporary learning theory (e.g. constructive, selfdirected, collaborative and contextual learning). ${ }^{9}$ Although electronic and class room learning may eliminate the need for rural visits, the results suggest that the efficacy of the PBL was directly linked to the experiential and contextual aspects derived from the rural visit, which led to increased knowledge and greater understanding and insight (e.g. into practical solutions to isolated practice). These same positive outcomes may not be present if trainees study a rural public health topic from an urban location. In addition, site visits can avoid some of the weaknesses related to distance learning such as content inflexibility ${ }^{10}$ and are an important part of a problem assessment.

The location, structure and suitability of the problems used to develop a rural PBL need consideration. In this case, the PBL within a retreat worked. The effectiveness of this experience may be related in part to the remote location of its delivery, which was very different from the trainees' usual experience and so captured their interest. A less isolated rural retreat may not have the same impact.

Other crucial ingredients for effectiveness appear to be collaboration between the NSW Public Health Officer 
Training Program, public health academics and public health practitioners at the planning and delivery stages. In this case, the lead academic involved with the development and delivery had a public health background, was familiar with the Program and had good relationships in Broken Hill. The PBL designers knew what a public health PBL should contain and how it should unfold. The PBL kept the interest of the trainees as it covered the technical, human and political aspects of the problem. Collaboration made the PBL real, with a variety of expertise contributing to the learning, the problem and the context. Despite the constructive planning process based on transparency and trust and the associated positive learning environment, additional stakeholder involvement by site managers at the planning stage would have assisted with managing expectations and role clarity during site visits.

While positive learning experiences have been associated with PBL, ${ }^{11-13}$ the satisfaction with the PBL and the rural retreat may be linked to the variety of learning modalities involved, including experiential learning - described elsewhere as 'significant' learning - as opposed to cognitive 'meaningless' learning. ${ }^{14}$ Such a mix would cater to the heterogeneity that exists in all groups, recognising that participants would not share the same learning style preference. $^{15}$

Satisfaction with the PBL appears to be derived in part from the study of a problem that requires active participation as opposed to problem simulation. ${ }^{4}$ The effectiveness of the PBL could also be due to the trainees being adult learners within a pre-existing well-formed group, which enabled them to quickly and productively focus on the topic. Because of the resources invested and the commitment by the trainees to be away from home, trainees may need to be 'made ready' for both the PBL and the retreat in order to maximise the learning opportunity. Not all groups may be as highly motivated or functional, so implementation issues, such as the level of problem structure and tutor directiveness, ${ }^{11}$ would need to be considered. Alternatively, the PBL might only be used where self-direction is assured. The model described, however, may work for other appropriately prepared public or primary health care staff involved in professional development.

\section{Conclusion}

Incorporating a public health PBL topic in a 1-week rural training retreat provides a positive learning experience for trainees undertaking postgraduate public health competency-based training. The value of a PBL within a rural retreat is linked to experiential learning where knowledge, insight and understanding are built with the potential to change individual practice and openness to work rurally. Rural educational retreats could play an important workforce role and should be considered for use with the range of health disciplines involved in such training.
A 1-week retreat with a single public health problem combined with good hospitality appears to be the right mix. Targeting motivated trainees at a level where they will be able to optimise the experience should be considered.

Preparatory work requires the design of a complex public health problem with appropriate site visits considered. Stakeholder involvement in planning will ensure roles are clear and expectations are managed. This style of learning should include orientation to the location and to the local public health unit staff so that trainees understand the organisational structures and resources available to practitioners. When evaluating the effectiveness of future public health training retreats, elements beyond learning domains should be considered, including the contextual elements of place and people. The question remains open as to whether this approach has a role in the broader implementation of the Program in both rural and non-rural settings.

To fully appreciate why this PBL was effective, comparative data from other rural training retreats involving PBL delivered for the Program is required. Such comparisons would identify the optimal range of sites and the suitability of public health problems.

\section{Acknowledgement}

The authors would like to thank all of the participants who contributed to the evaluation.

\section{References}

1. Hammel J, Royeen CB, Bagatell N, Chandler B, Jensen G, Loveland $\mathrm{J}$ et al. Student perspectives on problem-based learning in an occupational therapy curriculum: a multiyear qualitative evaluation. Am J Occup Ther 1999; 2: 199-206.

2. Mennin S, Gordan P, Majoor G, Osamn HAS. Position paper on problem-based learning. Educ Health (Abingdon) 2003; 16(1): 98-113. doi:10.1080/1357628031000066633

3. Norman GR, Schmidt HG. Effectiveness of problem-based learning curricula: theory, practice and paper darts. Med Educ 2000; 34: 721-8. doi:10.1046/j.1365-2923.2000.00749.x

4. Doucet MD, Purdy RA, Kaufman DM, Langille DB. Comparison of problem-based learning and lecture format in continuing medical education on headache diagnosis and management. Med Educ 1998; 32: 590-6. doi:10.1046/j.13652923.1998.00277.x

5. Pham KT, Blumberg P. Case design to emphasize population health concepts in problem-based learning. Educ Health (Abingdon) 2000; 13(1): 77-86. doi:10.1080/ 135762800110600

6. Spinello E, Fischbach R. Problem-based learning in public health instruction: a pilot study of an online simulation as a problem-based learning approach. Educ Health (Abingdon) 2004; 17(3): 365-73. doi:10.1080/13576280400002783

7. Fenwick T. Problem-based learning, group process and the mid-career professional: Implications for graduate education. Health Educ Res 2002; 21(1): 5-21. 
8. NSW Department of Health, Public Health Training and Development Unit. Informing public health practice competencies of the graduate diploma of applied epidemiology. State Health Publication No: (PHD) 000046. Sydney: NSW Department of Health, 2000.

9. Dolmans DHJM, DeGrave W, Wolfhagen IHAP, Van der Vleuten CPM. Problem-based learning: Future challenges for educational practice and research. Med Educ 2005; 39(7): 732-41. doi:10.1111/j.1365-2929.2005.02205.x

10. Nesbit T. Mapping adult education. Educ Theory 1999; 49(2): 265-79. doi:10.1111/j.1741-5446.1999.00265.x

11. Albanese M, Mitchell S. Problem-based learning: a review of literature on its outcomes and implementation issues. Acad Med 1993; 68(1): 52-81. doi:10.1097/00001888-19930100000012
12. Berkson L. Problem-based learning: have the expectations been met? Acad Med 1993; 68(Suppl): S79-88. doi:10.1097/00001888-199310000-00053

13. Vernon D, Blake R. Does problem-based learning work? A meta-analysis of evaluative research. Acad Med 1993; 68: 550-63. doi:10.1097/00001888-199307000-00015

14. Rogers C. Learning theories: Experiential learning. Available at http://www.educationau.edu.au/archives/cp/04f.htm. Accessed 24 February 2006.

15. Conner ML, Wright KC, DeVries L, Zeider C, Wilmsmeyer D, Forman D. Learning: the critical technology. Missouri: Wave Technologies International Inc., 1996. Available at www.wavetech.com/abt/abttmwp.htm. Accessed 1 August 2006.

\section{Use of communication technology among public health professionals in New South Wales, Australia}

\section{Carlie-Jane Naylor ${ }^{\mathrm{A}, \mathrm{C}}$, D. Lynne Madden ${ }^{\mathrm{A}}$ and Deborah J. Oong ${ }^{\mathrm{B}}$}

APublic Health Training and Development Branch, NSW Department of Health

${ }^{\mathrm{B}}$ Corporate Governance and Risk Management Branch, NSW Department of Health

${ }^{\mathrm{C}}$ Corresponding author.Email: carlie.naylor@doh.health.nsw.gov.au

\section{Introduction}

Communication technology plays an important role in health services in NSW, not only for the delivery of clinical services but also as a means of delivering training, holding meetings and sustaining networks. One reason for this is the large geographical size of NSW; it is divided into eight area health services, the largest of which covers $444586 \mathrm{~km}^{2}{ }^{1}$ Communication technology provides a means of linking health professionals across areas, and is particularly useful for those working in rural and remote communities. Even where distances are not large, these techniques also allow a more efficient use of time by reducing the need for travel.

Teleconferencing is frequently used for different types of meetings because it is readily available and easy to use. These features led Wildsoet et al. ${ }^{2}$ to pilot a continuing eduction program via teleconferencing to optometrists in rural Queensland. There are, however, limitations to teleconferencing. A randomised controlled trial compared teleconferencing with videoconferencing for the delivery of multidisciplinary case conferences. ${ }^{3}$ The trial found that there were more benefits with videoconferencing, and a small survey conducted with trial participants highlighted that having a visual component generated a high level of satisfaction in team members.

Videoconferencing is widely used in medicine for delivering clinical services such as mental health. ${ }^{4}$ In these clini- 